\title{
A (IM) PENHORABILIDADE SALARIAL SOB A ÉGIDE DO CÓDIGO DE PROCESSO CIVIL DE 2015
}

\author{
Fábio Dias da Silva ${ }^{1}$, Daniel Merizio Casati ${ }^{2}$ \\ ${ }^{1}$ Universidade Estadual de Londrina - UEL, Curso de Especialização em Direito Previdenciário. \\ ${ }^{2}$ Universidade do Oeste Paulista - UNOESTE, Curso de Direito. E-mail: dm_casati@hotmail.com; \\ fabiodiasilva@gmail.com.
}

\section{RESUMO}

A presente pesquisa tratou acerca da impenhorabilidade, ou não, das verbas salariais quando do advento do Código de Processo Civil de 2015, ao trazer um limite de impenhorabilidade destoante da realidade da economia brasileira. Assim, o objetivo do presente trabalho foi trazer à tona a penhorabilidade de verbas salariais, pouco importando o limite legal estabelecido. Pela metodologia empregada, a partir da dedução, passamos a constar que pela necessidade de uma entrega de tutela jurisdicional satisfativa, motiva ainda mais a relativização do instituto da impenhorabilidade. Pela exposição foi possível concluir que os 50 (cinquenta) salários mínimos não são padrão a se utilizar para declarar impenhorável determinada quantia, devendo resguardar a dignidade da pessoa humana do credor, mesmo que ocasione uma invasão patrimonial ao devedor.

Palavras-chave: Impenhorabilidade. Salário. Relativização. Penhora. Dignidade.

\section{(UN) ENFORCEABILITY UNDER THE AEGIS OF THE CIVIL PROCEDURE CODE OF 2015}

\begin{abstract}
The present study dealt with the impenorability or not of salary funds at the time of the Civil Procedure Code of 2015, by bringing a limit of unreliability to the reality of the Brazilian economy. Thus, the objective of the present study was to bring to the fore the garnability of salary funds, regardless of the legal limit established. According to the methodology used, from the deduction, we note that due to the need for a delivery of satisfactory judicial protection, it motivates even more the relativization of the institute of impenhorabilidad. Through the exhibition it was possible to conclude that the fifty (50) minimum salaries are not standard to be used to declare a certain amount unenforceable, and must safeguard the dignity of the human person of the creditor, even if it causes a patrimonial invasion of the debtor.
\end{abstract}

Keywords: Impenetrability. Salary. Relativization. Garnishment. Dignity. 


\section{INTRODUÇÃO}

Pela instituição das denominadas impenhorabilidades o ordenamento jurídico pátrio estabelece situações onde os atos executivos estarão mitigados, principalmente quando os efeitos da penhora não puderem ser colocados em prática pela existência de impedimentos legais ou convencionais.

E nesse ponto de pensamento coloca-se como necessária a possibilidade de que o juiz, ao exercer a jurisdição, adentrar no caso concreto e verificar que o limite estabelecido para a impenhorabilidade não deve ser respeitado, sob pena de trazer prejuízos à liquidez de uma execução judicial.

Com isso, o objetivo desse estudo foi trazer à baila a possibilidade e a penhorabilidade do salário do devedor, mesmo quando este perceber valor abaixo do montante legal pré-estabelecido para que o credor não detenha de um processo executivo ineficaz.

\section{DISCUSSÃO}

\section{PENHORA: CONCEITO, HIPÓTESES/ORDEM E EFEITOS JURÍDICOS}

Por conceito de penhora temos as lições trazidas por Araken de Assis (2016, p. 911) onde estabelece que "[...] é o ato executivo que afeta determinado bem à execução, permitindo sua ulterior expropriação, e torna os atos de disposição do seu proprietário ineficazes em face do processo".

Denota-se que a penhora é um instrumento pelo qual se terá a afetação dos bens do devedor para a garantia de um determinado débito exequendo, vislumbrando sempre a dignidade da pessoa do devedor, vezes que esse ato não pode levar à insolvência.

Ainda nesse ponto, verifica-se que esse ato torna o bem litigioso, não podendo o proprietário dispor de suas faculdades e direitos quando estiver afetado pela penhora, sob pena de se configurar um ato atentatório à dignidade da justiça, por criar embaraço a satisfação do débito executado, conforme redação do § 2. do artigo 77 do Código de Processo Civil.

A penhora, tal como o procedimento em fase de execução, se adequa ao interesse do jurisdicionado, transformando-o em um cumprimento forçado da decisão judicial proferida, nas concepções de Antonio Carlos de Araújo Cintra, Ada Pellegrini Grinover e Cândido Rangel Dinamarco (2010, p. 341) "o processo ou fase de execução visa a uma prestação jurisdicional consistente em tornar efetiva a sanção, mediante a prática dos atos próprios da execução forçada ou do cumprimento de sentença.".

Por essa forma de pensamento demonstra-se que a penhora é um instrumento de execução forçada pelo qual será adentrada na esfera patrimonial e pessoal do devedor, vislumbrando o adimplemento de um débito exequendo trazido em um título extrajudicial ou judicial, objetivando os interesses da jurisdição propriamente requerida pelo indivíduo.

Salta aos olhos que a penhora se atenta somente ao valor integral do débito do devedor, abrangendo o principal atualizado, custas, juros e honorários advocatícios, pela dicção do artigo 831 do Código de Processo Civil e, também, não se aplica aos bens considerados por lei como impenhoráveis e inalienáveis, consoante disposição do artigo 832 também do Código de Processo Civil.

O próprio ordenamento jurídico pátrio já delineia as hipóteses de penhora, adotando o critério excludente onde não se poderá ter qualquer penhora em bens inalienáveis e impenhoráveis seja por lei ou determinado pelas partes, como também traz uma ordem que pode ser adotada como hipóteses de penhora.

Assim, nos termos do artigo 835 do Código de Processo Civil pode ser penhorado todo e qualquer tipo de imóvel, móvel, ações, dinheiro, aplicações em instituições financeiras, percentual 
de faturamento da empresa devedora, títulos de valores imobiliários, ou seja, há uma elasticidade nas hipóteses de penhora.

De forma precisa o Código de Processo Civil traz um rol em que a ordem de penhora deve ser observada para o fim de que a tutela jurisdicional seja entregue da forma mais adequada e satisfatória aos interesses do credor e com os olhos na capacidade econômico-financeira do devedor, para que esse não seja posto em falência.

Nesse contexto, com a realização da penhora incorrerão diversos efeitos que, segundo Renato Montans de Sá (2016, p. 845-846) de forma didática os divide em processuais (prevenção executiva; garantia do juízo e direito de preferência) e materiais (desapossamento do bem e ineficácia dos atos de oneração/alienação).

Em adendo aos efeitos processuais, Araken de Assis (2016, p. 918) ensina que "[...] da penhora resulta o direito de o credor provocar a técnica expropriatória, a fim de transformá-lo em moeda corrente.".

É possível constatar que a utilização da técnica de expropriação se aplica somente aos bens que não são dotados de certa liquidez, sendo que o dinheiro, em espécie, aplicado ou disponível em conta bancária por si só já serve de garantia ao pagamento do débito exequendo para o credor.

Pelos ensinamentos da doutrina os efeitos processuais visam trazer, a princípio, a delimitação dos efeitos da penhora sobre o patrimônio do devedor, não podendo sua universalidade de bens ser posta sob penhora, salvo se o débito for de tamanha magnitude que não é possível retirar algum da execução.

Além disso, com a penhora se garantirá o juízo que, Renato Montans de Sá (2016, p. 845) ensina que "[...] diante do juízo de verossimilhança que se reveste o título, a garantia do juízo visa conferir equilíbrio na relação executiva, pois é grande a probabilidade de êxito do exequente, além de criar condições práticas para a satisfação do crédito.".

A penhora, ao servir de garantia do juízo, nada mais é do que uma forma com que a jurisdição requerida seja resguardada, não somente na entrega à tutela executiva requerida pelo credor como também de uma forma a proteger a eficácia das decisões jurisdicionais.

Outrossim, verificamos que pela penhora o credor (exequente) adquire a preferência sobre os bens penhorados, conforme dispõe o caput do artigo 797 do Código de Processo Civil e, também, com observação de Araken de Assis (2016, p. 918) ao estabelecer que "[...] o credor adquire a vantajosa posição de satisfazer integralmente seu crédito com o produto da venda do bem, $[\ldots]^{\prime \prime}$.

Mesmo que não haja o impedimento de que um bem penhorado não possa ser alvo de outras penhoras, decorrentes de outras demandas judiciais é certo que o credor que a realizar terá preferência quanto ao produto de sua venda.

Não obstante esses efeitos de índole processual, aqueles de ordem material se tratam, como já destacado, da impossibilidade de poder dispor do bem a qualquer tempo, uma vez penhorado, restringindo-se os direitos de propriedade e posse sobre o bem, além do fato de que retira da esfera direta de posse do devedor referido bem, nomeando-se depositário para tomar conta de sua integridade.

Um dos efeitos que merece destaque é que, uma vez realizada a penhora, torna litigiosa a coisa e, se colocada a registro, terá efeito erga omnes, ou seja, terceiros não poderão alegar o desconhecimento desse ato, haja vista o registro.

Por ser assim, a penhora se trata de um instrumento do procedimento de execução onde fará com que o direito do credor, à satisfação integral do débito, seja resguardado, desde que respeitados os limites impostos por lei e observada a dignidade da pessoa do devedor. 


\section{LIMITES DA PENHORA}

Pelo que foi destacado, a penhora detém de limites previamente estabelecidos por lei, desde o critério quantitativo, ou seja, de que somente recairá sobre os bens respeitando o limite do débito atualizado, acrescido de juros, multa e honorários advocatícios, até os limites da própria natureza do bem, excluindo desse ato os bens tidos como impenhoráveis e inalienáveis.

Sobre esse fato, denotamos que a inserção dos limites da penhora vai de encontro ao princípio da menor onerosidade e o do resultado, haja vista que ambos devem ter em vista a prestação da jurisdição de uma forma adequada e útil para as partes.

O princípio da menor onerosidade, assim, vem explanado no artigo 805 do Código de Processo Civil ao estabelecer que "quando por vários meios o exequente puder promover a execução, o juiz mandará que se faça pelo modo menos gravoso para o executado".

Com a imposição legal estabelecida vislumbra-se que há o interesse ao resguardo da dignidade da pessoa humana do executado, ainda mais quando os atos expropriatórios fizerem com que essa parte possa ser levada à miserabilidade, caso se exceda os limites de penhora.

No mesmo parâmetro o princípio do resultado, consoante ensinamentos de Araken de Assis (2016, p. 146) que dispõe que "[...] uma execução é bem-sucedida, de fato, quanto entrega rigorosamente ao exequente o bem da vida, objeto da prestação inadimplida, e seus consectários, ou obtém o direito reconhecido no título executivo (execução in natura). [...].".

De uma forma complementar temos que os princípios da menor onerosidade e do resultado, atrelados à atividade executiva, objetivam os interesses dos jurisdicionados, haja vista que a etapa da execução deve ser da forma menos gravosa possível e, de outro lado, deve trazer o resultado necessário para que se tenha a entrega da tutela jurisdicional de forma satisfativa e adequada.

Outrossim, os limites da penhora, aliado aos princípios supra destacados, visam balizar a responsabilidade patrimonial do devedor, conforme disposto no artigo 789 do Código de Processo Civil ao delinear que "o devedor responde com todos os seus bens presentes e futuros para 0 cumprimento de suas obrigações, salvo as restrições estabelecidas em lei".

Com a aplicabilidade da penhora, ressalvada as hipóteses de impenhorabilidade e inalienabilidade, essa poderá recair para com os bens presentes e futuro seja para o cumprimento de determinada obrigação, seja para o pagamento de determinada quantia.

Adverte, nesse ponto, Renato Montans de Sá (2016, p. 772):

[...] assim deve ser a interpretação do dispositivo: o devedor ou o responsável responde pelo cumprimento de suas obrigações com todos os seus bens presentes no momento da distribuição da execução. Responde também com os futuros, adquiridos na constância do processo, e com os passados, desde que a alienação esteja tipificada como fraude contra credores.

A exposição da doutrina impõe uma forma de se responsabilizar o devedor, visando à obtenção da satisfação do débito exequendo, haja vista que o devedor deve agir de boa-fé para com a prática de atos processuais de seus bens, como também trazendo à baila todos os bens presentes, futuros e passados, caso objeto de fraude contra credores.

Essas disposições nada mais refletem a norma fundamental de processo civil colocada no Código de Processo Civil de 2015, a qual disciplina, em seu artigo 8.ํ, que o juiz deve, ao aplicar o ordenamento jurídico ao caso concreto, resguardar e promover a dignidade da pessoa humana, bem como observando a eficiência do provimento jurisdicional a ser proferido.

Desta forma, observa-se que os limites da penhora são traçados pela impossibilidade de se dispor daqueles bens impenhoráveis e inalienáveis, como também deve se atrelar à responsabilidade patrimonial do devedor, sendo limitado esses atos ao valor do débito a ser 
executado, com um viés protetivo dos jurisdicionados quanto para a atividade jurisdicional requerida.

\section{A (IM) PENHORABILIDADE SALARIAL E O CÓDIGO DE PROCESSO CIVIL DE 2015}

Dentro dos limites da penhora, pelo que já foi salientado, temos a impossibilidade de que bens impenhoráveis por declaração expressa de vontade, ou por determinação legal, sejam alvos da satisfação de um débito de uma ação executiva.

Da impenhorabilidade de bens verificamos que o salário, tratado de uma forma abrangente pelo Código de Processo Civil de 2015, é uma hipótese de impenhorabilidade legal, ainda mais ao se tomar por base o caráter alimentar que se pressupõe.

Sob essa perspectiva temos o defendido por Daniel Amorim Assumpção Neves (2017, p. 1347) ao estabelecer que a impenhorabilidade de bens é a última das medidas no trajeto percorrido pela "humanização da execução" [...] colocando-se nesses casos sua dignidade humana em patamar superior à satisfação do direito do exequente. [...]".

A impenhorabilidade do salário, assim, visa proteger o devedor, nos moldes dos princípios da menor onerosidade e do resultado, de uma forma com que a execução tenha seus interesses resguardados sem que possa levar algum dos sujeitos à falência, ou até mesmo à coloca-lo em condições precárias.

Da mesma banda foi tutelada a preservação de resguardar o mínimo existencial para o ser humano, uma vez que quando o legislador vislumbra uma hipótese de impenhorabilidade, tal como o salário, objetiva reservar uma gama de direitos a garantir a sobrevivência do devedor e de seus dependentes/familiares, sem que prejudique o transcorrer de uma execução.

Caso o devedor somente tenha bens impenhoráveis sujeitos à satisfação do débito, de um modo que a execução não possa ter seu curso natural, pela inexistência de bens sujeitos à penhora, deve essa impenhorabilidade ser relativizada, mesmo que absoluta, até que o Código de Processo Civil de 2015 assim o fez, limitando a própria impenhorabilidade.

Nesse trilho, Nelson Nery Junior e Rosa Maria de Andrade Nery (2015, p. 1706) lecionam que "o rol das impenhorabilidades deve ser interpretado levando em consideração um equilíbrio entre os valores da personalidade e os da tutela jurisdicional prometida constitucionalmente.".

A interpretação da casuística deve ser adotada pelo órgão julgador para garantir a satisfação da atividade jurisdicional, de tal sorte que se não respeitada poderá ocasionar em um desrespeito tanto para o devedor (que poderá ser levado à insolvência) como também para o credor (quando a atividade executiva não será dada da forma como requerida, ao ocasionar a impenhorabilidade total de bens).

Dadas essas ressalvas que devem ser observadas pelo órgão jurisdicional, a partir do § 2.으 do artigo 833 do Código de processo Civil, vislumbramos que, no caso do salário, a impenhorabilidade é relativizada quando o devedor perceber quantias maiores do que 50 (cinquenta) salários mínimos.

Salta aos olhos que, se o devedor perceber a título de salário (leia-se, toda remuneração que percebe mensalmente a esse patamar) dentro do limite (50 (cinquenta) salários mínimos), estará livre de qualquer tipo de penhora, salvo quando se tratar de dívida de prestação alimentícia onde não é adotado esse valor.

Ora, o devedor que perceber o montante de $\mathrm{R} \$ 47.700,00$ (quarenta e sete mil e setecentos reais) não poderá ter qualquer penhora ao seu salário, ressalvada a dívida de pensão alimentícia, o que é um absurdo, visto que, ao se pautar do homem médio, referido valor é para uma classe social denominada " $A$ ", onde detém de renda mensal de $\mathrm{R} \$ 11.001,00$ (onze mil e um reais), segundo estudo extraído do sítio "VALOR ECONÔMICO". 
O que se constata é que o legislador não se pautou com o contexto de pobreza do Brasil, tendo em vista que a maior parte da população se enquadra nos parâmetros menores dos índices indicativos, e não sempre nos padrões de perceberem referida quantia mensal a título de salário.

Teresa Arruda Alvim Wambier et al (2015, p. 1183) preconiza que 50 (cinquenta) salários mínimos é demasiadamente alto para o padrão brasileiro, onde o legislador poderia deixar a cargo do juiz, com base no caso concreto, fixar uma porcentagem de penhora dos vencimentos do executado, com base na sua sobrevivência digna e da dignidade do exequente.

Com brilhantismo, e adequado ao pensamento defendido, a doutrina estabelece que não cabe estabelecer esse limite absurdo e fora dos parâmetros brasileiros para que livre o devedor que percebe tamanha quantia mensalmente dos deveres inerentes à sua pessoa como o pagamento do débito exequendo ao credor.

De tal sorte o que deve ser adotado é uma interpretação conjunta do caso concreto e do que a própria legislação dispõe, sob pena de se resguardar a dignidade da pessoa humana de um e rechaçar a de outro, ao se adotar da técnica da proporcionalidade e razoabilidade dos atos jurisdicionais.

A interpretação a ser adotada, assim, é a descrita por Eros Roberto Grau $(2016$, p. 83) ao dispor que "[...] a interpretação [...] há de ser concebida como atividade que adapta o direito às necessidades presentes e futuras da vida social (= atualiza-o), na acepção mais ampla dessa expressão".

Com essa premissa, devemos interpretar o interesse do legislador, ao trazer que a quantia monetária a ser penhorável, a título de salário, é aquela adequada aos parâmetros brasileiros, e não o exorbitante limite de 50 (cinquenta) salários mínimos, desde que com os olhos no caso concreto.

Araken de Assis (2016, p. 343), em caráter diverso, leciona que como não houve parâmetro interpretativo fixar o limite quantitativo, cabe ao órgão julgador ponderar os valores constitucionais envolvidos, podendo até dilatar o piso do excesso penhorável no caso concreto.

Com a devida vênia, não há como cogitar de que o órgão julgador torne impenhorável um valor acima de 50 (cinquenta) salários mínimos, mesmo que se trate de um custo de vida acima da média brasileira, uma vez que o exequente terá latente prejuízo na satisfação de seu crédito e, também, importará em uma conduta protetiva ao devedor.

O entendimento do Superior Tribunal de Justiça no REsp 1.285.970/SP de relatoria do Ministro Sidnei Beneti, Terceira Turma, DJe 08.09.2014 é a de que a regra contida na impenhorabilidade, compatibilizando esse entendimento ao novo Código de Processo Civil, deve ser excepcionada, levando em considerações o caso concreto, como a recalcitrância do devedor em adimplir o débito e de o desconto de $10 \%$ não acarretar em prejuízo financeiro latente.

Desse ponto, a Corte Superior de Justiça adota o critério interpretativo do caso concreto, aliada à situação posta em juízo, para que seja declarada a impenhorabilidade de determinadas verbas, ainda que dentro do limite exposto pelo legislador, haja vista o valor demasiadamente inserido no texto de lei.

De toda sorte, entende-se como necessário que se tenha uma interpretação concretamente adequada ao caso concreto, sopesando os valores tidos em juízo, de uma forma com que resguarde a dignidade do devedor sem que essa acarrete em prejuízos latentes à prestação jurisdicional requerida.

É certo que uma alternativa a essa impenhorabilidade seria a plena possibilidade de que se tenha uma porcentagem a ser retirada em juízo para que, de uma forma parcelada, o credor receba o valor exequendo, porém, deve se atentar ao interesse do exequente, sob pena de violar o princípio da inércia da jurisdição.

Assim sendo, não deve ser levado em consideração o entendimento adotado pelo legislador de 2015 ao preconizar o absurdo montante de 50 (cinquenta) salários mínimos para a 
penhora do salário recebido pelo devedor, devendo essa regra ser mitigada para que se resguarde a eficácia da execução, como também para que o credor tenha pelo menos a satisfação de seu crédito.

\section{CONCLUSÃO}

Pelo tudo que foi exposto é possível concluir que o limite de 50 (cinquenta) salários mínimos não deve ser respeitado, vezes que não condiz com a realidade econômico-financeira do Brasil e, também, que é um valor onde o próprio devedor pode se proteger quanto aos atos executivos de penhora, por exemplo.

Restou consignado, também, que a penhorabilidade de salário pode se dar não somente na totalidade dos recebimentos, podendo haver uma porcentagem a ser descontada mensalmente para a satisfação do débito exequendo, prevalecendo, assim, os princípios da menor onerosidade ao devedor e do resultado do processo executivo ao credor.

Por assim ser, não se trata de uma impenhorabilidade salarial, mas, sim, uma latente possibilidade de que o ato executivo de penhora, determinado pelo magistrado, quando requerido, pode atingir o salário do devedor, para que não sirva de escuro ao inadimplemento de uma execução.

\section{REFERÊNCIAS}

ASSIS, Araken de. Manual da execução. 18. ed. rev., atual. e ampl. São Paulo: Editora Revista dos Tribunais, 2016.

BÔAS, Bruno Villas. Estudos apontam que até 900 mil pessoas deixaram classes A e B. VALOR Econômico, Princípios Editoriais, 10 de maio de 2018. Disponível em: < https://www.valor.com.br/brasil/5515501/estudos-apontam-que-ate-900-mil-pessoas-deixaramclasses-e-b>. Acesso em: 06 ago. 2018.

BRASIL. Superior Tribunal de Justiça. RECURSO ESPECIAL. EXECUÇÃO. DÍVIDA APURADA EM INVENTÁRIO. OMISSÃO E AUSÊNCIA DE FUNDAMENTAÇÃO DO ACÓRDÃO RECORRIDO. INEXISTÊNCIA. PENHORA DE SALÁRIO. POSSIBILIDADE. Recurso Especial n. 1.285.970/SP. Recorrente: Paulo Antônio Chiavone. Recorrido: Ugo Di Cesare. Relator: Min. Sidnei Beneti. Terceira Turma. Brasília, 27 de maio de 2014, DJe 08.09.2014. Disponível em: < http://www.stj.jus.br/SCON/jurisprudencia/doc.jsp?livre=1285970\&b=ACOR\&p=true\&t=JURIDICO $\& \mathrm{l}=10 \& \mathrm{i}=12>$. Acesso em: 06 ago. 2018.

CINTRA, Antonio Carlos de Araújo; GRINOVER, Ada Pellegrini; DINAMARCO, Cândido Rangel. Teoria geral do processo. 26. ed., rev. e atual. São Paulo: Malheiros, 2010.

GRAU, Eros Roberto. Por que tenho medo de juízes: (a interpretação/aplicação do direito e os princípios) 7. ed. refundida do Ensaio e discurso sobre a interpretação / aplicação do direito. São Paulo: Malheiros, 2016.

NERY JUNIOR, Nelson; NERY, Rosa Maria de Andrade. Comentários ao código de processo civil. São Paulo: Revista dos Tribunais, 2015.

NEVES, Daniel Amorim Assumpção. Novo código de processo civil: comentado artigo por artigo. 2.ed., rev. e atual. Salvador, BA: JusPODIVM, 2017. 
SÁ, Renato Montans de. Manual de direito processual civil. 2. ed. São Paulo: Saraiva, 2016.

WAMBIER, Teresa Arruda Alvim et al. Primeiros comentários ao novo código de processo civil: artigo por artigo. São Paulo: Revista dos Tribunais, 2015. 